\begin{tabular}{|l|l|l||}
\hline \multicolumn{2}{|c|}{ PublisherInfo } \\
\hline \hline PublisherName & $:$ & BioMed Central \\
\hline \hline PublisherLocation & $:$ & London \\
\hline \hline PublisherImprintName & $:$ & BioMed Central \\
\hline \hline
\end{tabular}

\title{
Anemia and serum transferrin receptor in RA
}

\begin{tabular}{|l|l|l||}
\hline \multicolumn{2}{|c|}{ ArticleInfo } \\
\hline \hline ArticleID & $:$ & 154 \\
\hline \hline ArticleDOI & $:$ & $10.1186 /$ ar-2000-66842 \\
\hline \hline ArticleCitationID & $:$ & 66842 \\
\hline \hline ArticleSequenceNumber & $:$ & 111 \\
\hline \hline ArticleCategory & $:$ & Paper Report \\
\hline ArticleFirstPage & $:$ & 1 \\
\hline \hline ArticleLastPage & $:$ & 3 \\
\hline \hline & & RegistrationDate : 2000-9-14 \\
\hline ArticleHistory & $:$ & OnlineDate \\
\hline \hline ArticleCopyright & $:$ & Current Science Ltd2000-9-14 \\
\hline \hline ArticleGrants & $:$ & \\
\hline \hline ArticleContext & $:$ & 130753311 \\
\hline \hline
\end{tabular}


Aff1 University Hospital Berlin, Germany

\section{Keywords}

Anemia, RA, serum transferrin receptor

\section{Context}

In chronic inflammatory disease states anemia often develops as a consequence of the toxic effects of inflammatory mediators on erythropoiesis. This form of anemia is called anemia of chronic disease (ACD) and does not generally respond to iron supplementation in contrast to the excellent response to iron supplementation seen in iron deficiency anemia (IDA). A third form of anemia called functional iron deficiency (FID) shows a variable response to iron supplementation. Bone marrow iron stores are normal or elevated in ACD, exhausted in IDA and may be low to low-normal in FID. In chronic inflammation, ferritin as an acute-phase reactant is of no diagnostic value and bone marrow aspirate as gold standard is invasive and its use requires specialised skills. The use of serum transferrin receptor (sTfR) measurements and the sTfR-log ferritin index (TfR-F index) in the distinction between ACD and IDA has been proposed. To assess the usefulness of sTfR measurements to distinguish between IDA and ACD in RA.

This study aimed to establish a scheme to identify RA patients with FID who may benefit from iron supplementation.

\section{Significant findings}

Of 30 anemic RA patients the bone marrow was iron-replete in 11, iron-depleted in 13 and showed low to low-normal iron stores in six patients. After iron supplementation of the depleted/low normal group, 15 out of 18 (one patient withdrew) patients showed an increase in hemoglobin $>8 \mathrm{~g} / 1$ (mean 21.7 $\mathrm{g} / \mathrm{l})$ and were classified as responders. Reponders had a significant decrease in sTfR levels $(2.92 \mathrm{mg} / \mathrm{l}$ at baseline vs $2.06 \mathrm{mg} / 1$ at follow-up; $P<0.0001)$ and a decrease in their TfR-F index (2.26 vs $1.43 ; P$ $<0.0001$ ) whereas no such change was seen among non-responders and non-supplemented patients (sTfR $1.81 \mathrm{vs} 1.73 \mathrm{mg} / \mathrm{l}$, and TfR-F index 0.98 vs 1.08). The severity of the anemia did not correlate with the DAS28 in the responders (iron-depleted patients) whereas significant correlation was found in the iron-replete patients $(\mathrm{r}=0.69 ; P<0.01)$. The sTfR of $2.30 \mathrm{mg} / 1$ and a TfR-F index of 1.35 clearly discriminated between responders and non-responders in this patient group, each with a $93.3 \%$ accuracy. 


\section{Comments}

Anemia in chronic inflammatory disease can be a consequence of chronic inflammation or may reflect true iron deficiency. The recognition of true iron deficiency is of clear clinical relevance with respect to iron supplementation. The use of sTfR and the TfR-F index in this distinction has been elaborated by the authors in a previous study of healthy blood donors and is now extended to a population with rheumatoid arthritis. The data suggest that these markers may indeed be useful. However, no comparison was made between the performance of sTfR and the TfR-F index with other established and commonly applied markers of iron status such as transferrin saturation (see Additional information). Two further points need consideration. Firstly, several serum transferrin receptor assays are commercially available, some of which lack standardization, and results from different assays cannot be reliably compared with each other. Secondly, it is premature to base a treatment policy on the values which discriminate between iron deficiency and anemia of chronic disease in a single group drawn from one population. This observation should be replicated in a second cohort before general recommendations are issued. Despite these shortcomings, sTfR and the TfR-F index may become useful tools for the future management of anemic rheumatoid arthritis (RA) patients and possibly of other patients with chronic inflammatory disorders.

\section{Methods}

Thirty patients with active RA (mean DAS28 6.0) and anemia underwent bone marrow aspiration to determine the origin of their anemia. If their bone marrow was iron-depleted, patients received either a 16-week course of oral iron supplementation or a 12-week course of supplementation, starting after a 4-week observational period. If the marrow was iron-replete (normal to elevated iron stores), sTfR was measured using a novel commercial automated immunoturbidimetric method (Orion Diagnostica, Espoo, Finland). Ferritin, CRP and ESR were assessed according to standard methods.

\section{Additional information}

Besarab A, Amin N, Ahsan M, Vogel SE, Zazuwa G, Frinak S, Zazra JJ, Anandan JV, Gupta A: Optimization of epoetin therapy with intravenous iron therapy in hemodialysis patients. $J$ Am Soc Nephrol 2000, 11:530-538 (Original abstract).

\section{References}

1. Suominen P, Mottonen T, Rajamaki A, Irjala K: Single values of serum transferrin receptor and transferrin receptor ferritin index can be used to detect true and functional iron deficiency in rheumatoid arthritis patients with anemia. Arthritis Rheum. 2000, 43: 1016-1020. 